\title{
The Effects of Psychomotorik in the Forest on the Sensory and Visual Perception of Children with Intellectual Disabilities
}

\author{
Jin-Hee You' ${ }^{1}$ and Won-Sop Shin ${ }^{2 *}$ \\ ${ }^{1}$ Graduate Department of Forest Therapy, Chungbuk National University, Cheongju 28644, Korea \\ ${ }^{2}$ Department of Forestry, Chungbuk National University, Cheongju 28644, Korea
}

\begin{abstract}
The purpose of this study is to investigate the changes of sensory and visual perception of children with intellectual disabilities by conducting psychomotorik (psychomotor activity) in the forest and indoor treatment rooms. Accordingly, this study divided 18 children with intellectual disabilities living in the facility for persons with disabilities located in Seoul into three groups: the experimental group participating in psychomotorik in the forest, the comparative group participating in psychomotorik in the treatment room, and the control group without any treatment at all. The program was conducted for 32 weeks, 4 hours a month. The results showed that psychomotorik promoted the sensory and visual development of children with disabilities. Psychomotorik in the forest showed significant effects on touch and activity level, form constancy and eye-hand coordination. Psychomotorik in the treatment room showed significant improvement in figure-ground with reduced motion. This suggests that psychomotorik in the forest as well as indoors is a positive factor for sensory adaptation reaction and visual development of children with intellectual disabilities.
\end{abstract}

Keywords: developmental visual perception, forest experience, psychomotor activity, sensory profile

\section{Introduction}

Humans use sensory processing to perceive the outside world through physical movements and control their behaviors and emotions. Accurate perception is needed in order to move effectively, and this perceptual abilities are developed by movements and constantly interact with the environment. The body is a complex of the biological system and human motor development is both the cause and effect of various related systems. Each system must operate properly and harmoniously for movement, and to this end, there is a continuous interaction among the systems (Smith and Thelen, 2003). However, intellectual disabilities, which is a neurodevelopmental disorder, are defects that begin in the developmental stage of central nerves and cause maladjustment to overall 'life' (American Psychiatric Association, 2016). To develop the developmental delay and adaptability of children with disabilities, it is important to attempt voluntary movements in various environmental contexts (Schäfer, 1998). In other words, it is necessary to develop the abilities for

This study is conducted in 2018 with the request of Forest \& Kids supported by the Green Fund of the Korea Forest Welfare Institute.

Received: April 22, 2019, Revised: May 15, 2019, Accepted: May 22, 2019

First author: Jin-Hee You, E-mail: volustas@hanmail.net, (1) https://orcid.org/0000-0001-5010-6872

*Corresponding author: Won-Sop Shin, E-mail: shinwon@chungbuk.ac.kr, (1) https://orcid.org/0000-0002-5665-1502 
children with disabilities to perceive that their body is moving through movements.

Psychomotorik refers to psychological motive and human movements. It is defined as physical activity to achieve holistic development by building confidence and expressing oneself through voluntary experience, breaking away from meritocracy or performance with motor education suitable for humanistic development (Kiphard, 1989) According to Schilling (1986), the issues that appear in children's behaviors with regard to human movements are caused by lack of experience in movements. Thus, it is necessary to help children move voluntarily through interesting and structured movement tasks (Zimmer, 2005). Movements motivate both children with and without disabilities to participate in sensory training, body perception, space perception, prudence, self-regulation, rhythm-music training, physical and movement expression mediated by motility in the form of play, thereby achieving physical-mental balance (Kiphard, 1998). This psychomotorik is included in the field of developmental rehabilitation services since the enactment of the Act on Welfare Support for Children with Disabilities in 2011, and is now currently operated in welfare and treatment centers. It was proved that psychomotorik had positive effects on brain waves and behaviors of children with intellectual disabilities (Kim, 2017), improved sensory modulation and attention (Jeong and Rhie, 2011), and also improved coordination and adaptive behaviors of children with intellectual disabilities (Song, 2013). Psychomotorik promotes holistic development such as physical, cognitive, and social adaptive behaviors by stimulating the senses and movements.

Forest activities satisfy young children's needs to move without space constraints, and enable them to discover new things by moving (Köllner and Leinert, 1998). Moreover, they promote children's interests, adventures and explorations in the forest where there are diverse environments, and give countless opportunities of sensory experience, movement control and interaction with others by moving freely (Andersen, 1996). Young children playing in a natural space are better at exercises and have more developed sense of balance and gross motor skills than those playing in an intentionally designed facility (Fjørtoft, 2001, 2004). As such, activities using the sensations and topography of forests may promote young children's physical development and curiosity.

Bradley and Male (2017) studied children with disabilities and discovered that forest schools have potential to provide actual experience of learning and social facilitation for children with autism spectrum. A fingertip play program using natural objects in the forest developed fine motor skills of young children with brain lesions (Chung, 2014), and an outdoor adventure program improved communication of young children with autism spectrum (Zachor et al., 2017). Moreover, forest activities were proved to have positive effects on hyperactive-impulsive, learning-inattentive, and anxiety of children with ADHD (Hong et al., 2016), and on motor ability and prosocial behavior of children with developmental disabilities (Jo et al., 2016). This indicates that activities such as sensory movements in the forest promote physical, language/cognitive, emotional and social development of children with disabilities, and that the forest can be used for education and rehabilitation.

Forests must be for everyone as universal welfare, and thus it is necessary to constantly increase forest accessibility for the underprivileged and persons with disabilities and to develop programs that meet their needs. There are research findings about the development of children with disabilities using forest activities, but none are related to developmental rehabilitation services. Thus, this study will verify the effectiveness of psychomotorik based on forests in association with developmental rehabilitation services provided by the Ministry of Health and Welfare for children with disabilities.

\section{Research Methods}

\section{Subjects}

The subjects were 18 children with class 1-3 intellectual disabilities in D living facility for persons with disabilities 
in Seoul, selecting those recommended by the facility who verbally agreed to participate. They were randomly assigned into three groups considering the chronological age and social age calculated by measuring social maturity (Kim and Kim, 1989) as shown in Table 1.

\section{Experiment methods and tools}

\section{Research design}

Prior to the study, a pre-test was conducted in 18 sessions on 10 children with intellectual disabilities to determine the possibility and validity. The result showed that forest psychomotorik had a positive effect on sensory processing and modulation, motility, and development of visual perception. Thus, three groups were selected, assuming that it is possible to obtain results that meet the purpose of research. The experimental group participated in psychomotorik in the forest, the comparative group participated in psychomotorik in the treatment room (indoors), and the control group did not participate in the program. The program was conducted for 32 weeks from March 25 to October 21, 2018, and it was carried out 4 hours a month based on the time for which the Ministry of Health and Welfare provides vouchers for developmental rehabilitation services. Experimental group participated in the program for 16 sessions, 2 hours every other week in the forest, and comparative group participated in the program for 32 sessions, 1 hour every week in the treatment room. Table 2 shows the research process and relevant measure.

\section{Tools}

\section{(1) Sensory Profile}

The Sensory Profile is a tool evaluating the sensory processing skills related to task performance in daily life (Dunn, 1997). The test is conducted in the form of interview and survey on the subject's caregiver. There are total 125 items assessed by obtaining the total score of each item in the three sensory sections and nine sensory factors, with the results interpreted in three categories: typical performance, probable difference, and definite difference. The internal consistency Cronbach's $\alpha$ of the Sensory Profile is .47-.91, and the reliability coefficient of the overall scale is .728. In

Table 1. Characteristics of participants

\begin{tabular}{lcccccc}
\hline \multirow{2}{*}{ Division } & \multicolumn{2}{c}{ Experimental group $(\mathrm{n}=6)$} & \multicolumn{2}{c}{ Comparative group $(\mathrm{n}=6)$} & \multicolumn{2}{c}{ Control group $(\mathrm{n}=6)$} \\
& $\mathrm{M}$ & $\mathrm{SD}$ & $\mathrm{M}$ & $\mathrm{SD}$ & $\mathrm{M}$ & $\mathrm{SD}$ \\
\hline Chronological age (year) & 10.65 & 2.21 & 11.20 & 2.26 & 11.46 & 2.06 \\
Social age $^{\mathrm{z}}$ (year) & 6.96 & 2.13 & 6.99 & 3.84 & 6.81 & 2.20 \\
\hline
\end{tabular}

${ }^{\mathrm{z}}$ Social age was determined by Vineland Social Maturity Scale (SMS).

Table 2. Research design and relevant measure

\begin{tabular}{|c|c|c|c|c|c|}
\hline Division & Period & Pre-test & Program execution & Post-test & Test item \\
\hline Experimental group $(n=6)$ & \multirow{3}{*}{$\begin{array}{c}\text { March } 25- \\
\text { October } 15,2018 \\
\text { (for } 32 \text { weeks) }\end{array}$} & $\mathrm{O}_{1}$ & $X_{1}$ & $\mathrm{O}_{2}$ & \multirow{3}{*}{$\begin{array}{c}\text { Sensory Profile } \\
\text { K-DTVP-2 }\end{array}$} \\
\hline Comparative group $(n=6)$ & & $\mathrm{O}_{1}$ & $\mathrm{X}_{2}$ & $\mathrm{O}_{2}$ & \\
\hline Control group $(n=6)$ & & $\mathrm{O}_{1}$ & & $\mathrm{O}_{2}$ & \\
\hline
\end{tabular}

Note. $\mathrm{O}_{1}=$ pre-test performed; $\mathrm{O}_{2}=$ post-test performed; $\mathrm{X}_{1}=$ psychomotorik program in the forest; $\mathrm{X}_{2}=$ psychomotorik program in the treatment room. K-DTVP-2 = Korean Developmental Test of Visual Perception-2. 
this study, the rehabilitation teacher in charge wrote the checklist.

(2) Korean Developmental Test of Visual Perception-2 (K-DTVP-2)

Hammill et al. (1992) standardized the Developmental Test of Visual Perception (DTVP) by Frostig developed in 1961 and came up with DTVP-2. Moon et al. (2003) translated into the Korean version and standardized K-DTVP-2. This tool measures visual perception and visual-motor skills, and can diagnose disability in the actual visual perception system of infants and children showing learning difficulties. Based on the theory of perception, it is comprised of six subordinate tests such as copying, figure-ground, visual-motor exploration, visual closure, visual-motor speed, and form constancy. Cronbach's $\alpha$ of the tests is .74-.87, and the reliability coefficient of the overall scale is .83. In this study, the clinical counselor conducted the one-on-one test on children with disabilities.

\section{Study areas and forest psychomotorik program}

(1) Group study areas

The experimental group in the living welfare facility for persons with disability located in Seocho-gu participated in the study at the forest created within the forest and the Beombawi Rock mountain within a $200 \mathrm{~m}$ radius, where the main tree species are Prunus serrulata var. spontanea, Pinus strobus L., Quercus acutissima Carruth, Quercus variabilis Blume, Robinia pseudo-acacia L.. The comparative group participated in the study at the indoor treatment center within the same facility with the area of $50 \mathrm{~m}^{2}$ and furnished with activity tools that promote various senses and movements such as mats, slides, trampolines and swings. The control group did not participate in the program and is a group engaged in everyday life living in the same facility. Table 3 shows the topography and activities of the study areas.

(2) Forest psychomotorik program

Sensory exploration through body, material and social experiences as well as movement play and activities in sea-

Table 3. Place analysis by group

$\begin{array}{lll}\text { Division } & \begin{array}{c}\text { Starting place } \\ \text { (landform) }\end{array} & \begin{array}{c}\text { Vestibular sense } \\ \text { (swing, stair) }\end{array}\end{array}$


sonal themes were carried out through the psychomotorik approach, and the program structure is as shown in Table 4. Moreover, sensory and visual perception accelerators were analyzed to individually support activities for children with disabilities, and the program intervention is as shown in Table 5.

\section{Data processing}

First, normal distribution was not satisfied as a result of the Shapiro-Wilk test to test the normality of the test re-

Table 4. Composition of psychomotorik in forest activities

\begin{tabular}{|c|c|c|}
\hline Time & Activity content & Contents \\
\hline $\begin{array}{l}\text { Introduction } \\
(30 \mathrm{~min})\end{array}$ & - Greeting \& opening body (energy expression) and mind & $\begin{array}{l}\text { Body experience: } \\
\text { sensory (cognitive) }\end{array}$ \\
\hline \multirow{3}{*}{$\begin{array}{l}\text { Program application } \\
(120 \mathrm{~min})\end{array}$} & $\begin{array}{l}\text { - Movement play } \\
\text { - Movement and sensation promotion using natural objects and terrain around }\end{array}$ & \multirow{3}{*}{$\begin{array}{l}\text { Body experience: movement } \\
\text { Material experience: } \\
\text { sensory (cognitive) } \\
\text { motion (experience) } \\
\text { Social experience: } \\
\text { creativity (play) } \\
\text { Child-centered }\end{array}$} \\
\hline & $\begin{array}{l}\text { - Sensory exploration \& motion sensation } \\
\text { - Activities that are mediated through free activity and sensory integration }\end{array}$ & \\
\hline & $\begin{array}{l}\text { - Activity theme programs } \\
\text { - Forest ecology story based on monthly theme }\end{array}$ & \\
\hline $\begin{array}{l}\text { Wrap-up } \\
(30 \text { min })\end{array}$ & $\begin{array}{l}\text { - Physical relaxation \& meet heart } \\
\text { - Music \& body contact massage } \\
\text { - Sharing emotions and thoughts }\end{array}$ & $\begin{array}{l}\text { Body } \cdot \text { material } \cdot \text { social } \\
\text { experience: conversation }\end{array}$ \\
\hline
\end{tabular}

Table 5. Intervention of psychomotorik in forest activity

\begin{tabular}{|c|c|c|c|c|c|c|c|c|c|c|c|c|}
\hline \multirow{3}{*}{ Session } & \multirow{3}{*}{ Program goal } & \multirow{3}{*}{ Activity theme } & \multicolumn{10}{|c|}{ Supporting objective } \\
\hline & & & \multicolumn{2}{|c|}{ Sense } & \multicolumn{4}{|c|}{ Visual perception } & \multicolumn{4}{|c|}{ Visual motion } \\
\hline & & & In & Ext & PS & $\mathrm{FG}$ & $\mathrm{VC}$ & $\mathrm{FC}$ & $\mathrm{EH}$ & $\mathrm{CO}$ & SR & VMS \\
\hline \multirow{3}{*}{1 to 3} & \multirow{3}{*}{$\begin{array}{l}\text { Intimacy formation } \\
\text { Recognition of forest spaces } \\
\text { and natural objects }\end{array}$} & Walking in the forest & $\bullet$ & $\bullet$ & $\bullet$ & $\bullet$ & $\bullet$ & (2) & () & () & $\bullet$ & () \\
\hline & & Forest roads we found & $\bullet$ & $\bullet$ & $\bullet$ & $\bullet$ & () & (C) & $\bullet$ & () & (C) & () \\
\hline & & Create a hideout & $\bullet$ & - & $\bullet$ & $\bullet$ & • & $\bullet$ & $\bullet$ & () & $\bullet$ & () \\
\hline \multirow{10}{*}{4 to 13} & \multirow{10}{*}{$\begin{array}{l}\text { Body adjustment in space } \\
\text { Recognize foreground and } \\
\text { background and distinguish } \\
\text { - Manipulation activity } \\
\text { through coordinated action } \\
\text { Body movement speed } \\
\text { control }\end{array}$} & Gentle handling of the wind & $\bullet$ & $\bullet$ & $\bullet$ & () & $\bullet$ & () & $\bullet$ & () & $\bullet$ & $\bullet$ \\
\hline & & Pairs of natural objects & $\bullet$ & $\bullet$ & (2) & $\bullet$ & () & $\bullet$ & $\bullet$ & $\bullet$ & $\bullet$ & () \\
\hline & & Let's meet a tree & $\bullet$ & $\bullet$ & $\bullet$ & $\bullet$ & () & (2) & $\bullet$ & $\bullet$ & (a) & () \\
\hline & & Drop it & $\bullet$ & $\bullet$ & () & () & $\bullet$ & $\bullet$ & $\bullet$ & () & () & $\bullet$ \\
\hline & & Go straight ahead & $\bullet$ & $\bullet$ & () & (C) & $\bullet$ & () & $\bullet$ & $\bullet$ & $\bullet$ & () \\
\hline & & Let's make a web & $\bullet$ & $\bullet$ & $\bullet$ & $\bullet$ & $\bullet$ & () & $\bullet$ & $\bullet$ & $\bullet$ & $\bullet$ \\
\hline & & We need water & $\bullet$ & $\bullet$ & $\bullet$ & () & $\bullet$ & () & $\bullet$ & () & () & $\bullet$ \\
\hline & & Cicada chirping & $\bullet$ & $\bullet$ & $\bullet$ & $\bullet$ & $\bullet$ & $\bullet$ & $\bullet$ & () & () & () \\
\hline & & Let's be cicadas & $\bullet$ & - & () & $\bullet$ & $\bullet$ & $\bullet$ & $\bullet$ & () & $\bullet$ & $\bullet$ \\
\hline & & Transformation of a tree & $\bullet$ & $\bullet$ & $\bullet$ & $\bullet$ & () & $\bullet$ & $\bullet$ & $\bullet$ & (0) & (2) \\
\hline \multirow{3}{*}{14 to 16} & \multirow{3}{*}{$\begin{array}{l}\text { Visual information } \\
\text { integration }\end{array}$} & Things falling out of trees & $\bullet$ & $\bullet$ & $\bullet$ & $\bullet$ & $\bullet$ & () & $\bullet$ & () & $\bullet$ & $\bullet$ \\
\hline & & Rolling acorn & $\bullet$ & $\bullet$ & $\bullet$ & $\bullet$ & $\bullet$ & $\bullet$ & $\bullet$ & $\bullet$ & $\bullet$ & $\bullet$ \\
\hline & & Walking in the forest & $\bullet$ & $\bullet$ & $\bullet$ & $\bullet$ & $\bullet$ & () & () & () & $\bullet$ & () \\
\hline
\end{tabular}

Note. In = inner sensation; Ext = external sensation; PS = position in space; FG = figure-ground; VC = visual closure; FC = form constancy; $\mathrm{EH}=$ eye-hand coordination; $\mathrm{CO}=$ copying; $\mathrm{SR}=$ spatial relation; $\mathrm{VMS}=$ visual-motor speed.

$\bullet=$ high intensity activity; $($ ) = moderate intensity activity. 
sult of each sample. Thus, homogeneity was tested using the non-parametric method of the Krukal-Wallis test on scores of social age, sensory and visual perception. Second, to determine the difference in sensory processing, modulation and visual perception within the group, the changes in the pretest-posttest scores were examined using the non-parametric method of the Wilcoxon signed rank test. Third, the Krukal-Wallis test was conducted by calculating the pretest-posttest score differences to determine the differences among groups, followed by the Bonferroni correction test with the significance level at $p<.05$. The collected data were analyzed using the SPSS WIN 18.0 program.

\section{Results and Discussion}

\section{Homogeneity test among groups}

Before the program, the non-parametric method of the Krukal-Wallis test was conducted to analyze homogeneity among the experimental, comparative and control group. There was no statistically significant difference in the mean scores of all sub-items of the Sensory Profile and DTVP, thereby proving that the three groups are homogenous, and the results are as shown in Table 6.

\section{Effects of forest psychomotorik on sensory processing and modulation}

\section{Effects on sensory processing and modulation within the group}

The results of testing the pretest-posttest score changes to determine the adaptation reaction changes in sensory pro-

Table 6. Results from the homogeneity test among groups

\begin{tabular}{|c|c|c|c|c|c|c|}
\hline \multirow{2}{*}{\multicolumn{2}{|c|}{ Scale (sub-item) }} & \multicolumn{3}{|c|}{$\mathrm{M} \pm \mathrm{SD}$} & \multirow{2}{*}{$\chi^{2}$} & \multirow{2}{*}{$p$} \\
\hline & & Experimental group & Comparative group & Control group & & \\
\hline \multirow{10}{*}{$\begin{array}{l}\text { Sensory } \\
\text { Profile }\end{array}$} & Auditory & $32.33 \pm 5.46$ & $27.83 \pm 5.41$ & $29.16 \pm 4.57$ & 1.19 & $.383^{\mathrm{NS}}$ \\
\hline & Visual & $35.66 \pm 5.39$ & $35.50 \pm 2.58$ & $39.33 \pm 5.83$ & 3.83 & $.147^{\mathrm{NS}}$ \\
\hline & Vestibular & $44.16 \pm 6.11$ & $44.00 \pm 9.25$ & $45.16 \pm 6.08$ & 0.21 & $.897^{\mathrm{NS}}$ \\
\hline & Touch & $75.50 \pm 9.81$ & $65.00 \pm 13.75$ & $78.33 \pm 5.60$ & 3.37 & $.185^{\mathrm{NS}}$ \\
\hline & Multisensory & $27.33 \pm 4.41$ & $26.83 \pm 16.01$ & $25.00 \pm 1.54$ & 0.70 & $.704^{\mathrm{NS}}$ \\
\hline & Oral & $56.16 \pm 5.20$ & $50.16 \pm 7.65$ & $54.50 \pm 4.80$ & 2.35 & $.307^{\mathrm{NS}}$ \\
\hline & Endurance/tone & $38.33 \pm 7.14$ & $31.83 \pm 9.51$ & $31.00 \pm 10.54$ & 3.38 & $.184^{\mathrm{NS}}$ \\
\hline & Position \& movement & $38.50 \pm 5.08$ & $37.00 \pm 6.44$ & $38.83 \pm 4.83$ & 0.37 & $.829^{\mathrm{NS}}$ \\
\hline & Activity level & $21.16 \pm 2.31$ & $20.66 \pm 5.08$ & $22.16 \pm 1.60$ & 0.67 & $.713^{\mathrm{NS}}$ \\
\hline & Sensory input & $13.50 \pm 1.87$ & $12.16 \pm 2.71$ & $13.16 \pm 2.22$ & 1.36 & $.506^{\mathrm{NS}}$ \\
\hline \multirow{9}{*}{ DTVP } & Visual input & $14.00 \pm 2.28$ & $12.83 \pm 2.78$ & $15.66 \pm 2.70$ & 3.91 & $.141^{\mathrm{NS}}$ \\
\hline & Position in space & $3.83 \pm 2.48$ & $4.00 \pm 3.16$ & $3.50 \pm 3.56$ & 1.00 & $.604^{\mathrm{NS}}$ \\
\hline & Figure-ground & $4.83 \pm 3.06$ & $5.33 \pm 1.36$ & $5.83 \pm 3.18$ & 0.65 & $.722^{\mathrm{NS}}$ \\
\hline & Visual closure & $4.83 \pm 4.02$ & $3.66 \pm 3.77$ & $4.00 \pm 3.94$ & 0.28 & $.868^{\mathrm{NS}}$ \\
\hline & Form constancy & $6.00 \pm 2.28$ & $6.66 \pm 1.03$ & $6.44 \pm 2.80$ & 0.42 & $.808^{\mathrm{NS}}$ \\
\hline & Eye-hand coordination & $2.50 \pm 1.87$ & $3.00 \pm 1.54$ & $3.00 \pm 1.54$ & 0.85 & $.652^{\mathrm{NS}}$ \\
\hline & Copying & $7.00 \pm 2.60$ & $6.66 \pm 3.14$ & $6.66 \pm 3.93$ & 0.30 & $.860^{\mathrm{NS}}$ \\
\hline & Spatial relation & $3.50 \pm 3.50$ & $3.16 \pm 3.43$ & $3.66 \pm 3.44$ & 0.09 & $.953^{\mathrm{NS}}$ \\
\hline & Visual-motor speed & $7.66 \pm 3.88$ & $7.83 \pm 1.72$ & $7.50 \pm 2.82$ & 0.32 & $.850^{\mathrm{NS}}$ \\
\hline
\end{tabular}

Note. DTVP=Developmental Test of Visual Perception.

${ }^{\mathrm{NS}}$ Non-significant. 
cessing and modulation within the group are as follows. First, for sensory processing, there was a significant effect on auditory $(\mathrm{z}=-2.23, p=.020)$, visual $(\mathrm{z}=-2.06, p=.039)$, vestibular $(\mathrm{z}=-2.23, p=.025)$, and touch $(\mathrm{z}=-2.06, p=.039)$ in the experimental group, and auditory $(\mathrm{z}=-2.25, p=.024)$, visual $(\mathrm{z}=-2.00, p=.046)$, and vestibular $(\mathrm{z}=-2.07, p=$ .038 ) in the comparative group. Second, for sensory modulation, there was a significant effect on position \& movement $(\mathrm{z}=-2.06, p=.039)$, activity level $(\mathrm{z}=-2.26, p=.024)$, sensory input $(\mathrm{z}=-2.07, p=.038)$, and visual input $(\mathrm{z}=-2.23$, $p=.025)$ in the experimental group, and position \& movement $(\mathrm{z}=-2.25, p=.024)$, sensory input $(\mathrm{z}=-2.23, p=.025)$, and visual input $(\mathrm{z}=-2.00, p=.046)$ in the comparative group (Table 7).

Table 7. Changes in sensory processing and modulation after psychomotorik program within the group

\begin{tabular}{|c|c|c|c|c|c|c|}
\hline \multirow{2}{*}{ Sub-item } & & \multirow{2}{*}{ Group $^{z}$} & \multicolumn{2}{|c|}{$\mathrm{M} \pm \mathrm{SD}$} & \multirow{2}{*}{$\mathrm{z}$} & \multirow{2}{*}{$p$} \\
\hline & & & Pre & Post & & \\
\hline \multirow{18}{*}{$\begin{array}{l}\text { Sensory } \\
\text { processing }\end{array}$} & \multirow{3}{*}{ Auditory } & Experimental & $32.33 \pm 5.46$ & $33.50 \pm 5.54$ & -2.23 & $.020^{*}$ \\
\hline & & Comparative & $27.83 \pm 5.41$ & $29.33 \pm 4.96$ & -2.25 & $.024^{*}$ \\
\hline & & Control & $29.16 \pm 4.57$ & $29.33 \pm 4.63$ & -1.00 & .317 \\
\hline & \multirow{3}{*}{ Visual } & Experimental & $35.66 \pm 5.39$ & $37.00 \pm 5.83$ & -2.06 & $.039^{*}$ \\
\hline & & Comparative & $35.50 \pm 2.58$ & $36.16 \pm 2.92$ & -2.00 & $.046^{*}$ \\
\hline & & Control & $39.33 \pm 5.83$ & $39.50 \pm 3.72$ & 0.00 & 1.000 \\
\hline & \multirow{3}{*}{ Vestibular } & Experimental & $44.16 \pm 6.11$ & $45.83 \pm 6.49$ & -2.23 & $.025^{*}$ \\
\hline & & Comparative & $44.00 \pm 9.25$ & $45.33 \pm 8.82$ & -2.07 & $.038^{*}$ \\
\hline & & Control & $45.16 \pm 6.08$ & $45.83 \pm 6.24$ & -2.00 & $.046^{*}$ \\
\hline & \multirow{3}{*}{ Touch } & Experimental & $75.50 \pm 9.81$ & $77.16 \pm 8.35$ & -2.06 & $.039^{*}$ \\
\hline & & Comparative & $65.00 \pm 13.75$ & $68.00 \pm 13.57$ & -1.34 & .180 \\
\hline & & Control & $78.33 \pm 5.60$ & $78.50 \pm 5.82$ & -1.00 & .317 \\
\hline & \multirow{3}{*}{ Multisensory } & Experimental & $27.33 \pm 4.41$ & $28.16 \pm 4.75$ & -1.63 & .102 \\
\hline & & Comparative & $26.83 \pm 16.01$ & $27.16 \pm 5.52$ & -1.00 & .317 \\
\hline & & Control & $25.00 \pm 1.54$ & $24.66 \pm 1.57$ & -.447 & .655 \\
\hline & \multirow{3}{*}{ Oral } & Experimental & $56.16 \pm 5.26$ & $56.33 \pm 5.42$ & -1.00 & .317 \\
\hline & & Comparative & $50.16 \pm 7.65$ & $50.16 \pm 7.65$ & 0.00 & .317 \\
\hline & & Control & $54.50 \pm 4.80$ & $54.66 \pm 4.50$ & -1.00 & .317 \\
\hline \multirow{15}{*}{$\begin{array}{l}\text { Sensory } \\
\text { modulation }\end{array}$} & \multirow{3}{*}{ Endurance/tone } & Experimental & $38.33 \pm 7.14$ & $39.33 \pm 6.40$ & -1.85 & .063 \\
\hline & & Comparative & $31.83 \pm 9.51$ & $32.50 \pm 10.13$ & -1.63 & .102 \\
\hline & & Control & $31.00 \pm 10.54$ & $31.66 \pm 9.50$ & -1.63 & .102 \\
\hline & \multirow{3}{*}{ Position \& movement } & Experimental & $38.50 \pm 5.08$ & $40.66 \pm 5.20$ & -2.06 & $.039^{*}$ \\
\hline & & Comparative & $37.00 \pm 6.44$ & $38.50 \pm 6.09$ & -2.25 & $.024^{*}$ \\
\hline & & Control & $38.83 \pm 4.83$ & $39.50 \pm 5.08$ & -1.63 & .102 \\
\hline & \multirow{3}{*}{ Activity level } & Experimental & $21.16 \pm 2.31$ & $23.16 \pm 2.31$ & -2.26 & $.024^{*}$ \\
\hline & & Comparative & $20.66 \pm 5.08$ & $21.00 \pm 4.93$ & -1.00 & .317 \\
\hline & & Control & $22.16 \pm 1.60$ & $23.16 \pm 1.72$ & -1.85 & .063 \\
\hline & \multirow{3}{*}{ Sensory input } & Experimental & $13.50 \pm 1.87$ & $14.66 \pm 2.06$ & -2.07 & $.038^{*}$ \\
\hline & & Comparative & $12.16 \pm 2.71$ & $13.00 \pm 2.36$ & -2.23 & $.025^{*}$ \\
\hline & & Control & $13.16 \pm 2.22$ & $13.66 \pm 2.06$ & -1.73 & .083 \\
\hline & \multirow{3}{*}{ Visual input } & Experimental & $14.00 \pm 2.28$ & $14.83 \pm 2.13$ & -2.23 & $.025^{*}$ \\
\hline & & Comparative & $12.83 \pm 2.78$ & $13.50 \pm 3.01$ & -2.00 & $.046^{*}$ \\
\hline & & Control & $15.66 \pm 2.70$ & $15.50 \pm 2.88$ & -.577 & .564 \\
\hline
\end{tabular}

${ }^{\mathrm{z}} \mathrm{n}=6$ in each group.

${ }^{*} p<.05$. 
Psychomotorik in the forest and indoors showed significant changes in visual and auditory processing, position \& movement, sensory input and visual perception input. This is a brain action due to the performance of perceived task in the middle of sensory and cognitive processing, which shows that sensory activities promote perception and stimulate cognitive development (Witt et al., 1988). Moreover, psychomotorik in the forest significantly improved touch and activity level, showing similar results with Andersen (1996) who proved that various sensory stimulations improve position and movement more than indoor activities.

\section{Verification of the differences in sensory processing and modulation among groups}

As a result of calculating and testing the pretest-posttest score differences to determine the difference among groups, there were significant differences among groups in sensory processing such as auditory $\left(\chi^{2}=10.96, p=.004\right)$, visual $\left(\chi^{2}=8.84, p=.012\right)$, and touch $\left(\chi^{2}=8.27, p=.016\right)$ processing, and sensory modulation such as activity level $\left(\chi^{2}=8.84\right.$, $p=.012$ ). The experimental group showed a more significant increase in auditory, visual, touch, and activity level than the control group, and in touch and activity level than the comparative group (Table 8).

Previous studies also showed similar results in that psychomotorik improved sensory modulation (Jeong and Rhie, 2011) and movement activities in the forest have positive effects on improving sensory processing and modulation (Kang, 2019). These results are the outcomes of touching and experiencing natural objects with various senses and stimulating the physical and activity level through diverse topographies and movements, thereby showing more effects than the indoor comparative group and the control group.

\section{Effects of forest psychomotorik on visual perception}

\section{Effects on visual perception and visual motion within the group}

The results of testing the pretest-posttest score changes to determine the visual perception and visual motion changes within the group are as follows. First, for visual perception, there was a significant effect on visual closure $(\mathrm{z}=-2.07$, $p=.038)$ and form constancy $(\mathrm{z}=-2.33, p=.020)$ in the experimental group, and position in space $(\mathrm{z}=-2.12, p=.034)$ and figure-ground $(\mathrm{z}=-2.17, p=.023)$ in the comparative group. Second, for visual motion, there was a significant ef-

Table 8. Verification of the differences in sensory processing and modulation after psychomotorik program among groups

\begin{tabular}{|c|c|c|c|c|c|c|c|}
\hline \multirow{2}{*}{ Sub-item } & & \multicolumn{3}{|c|}{$\mathrm{M} \pm \mathrm{SD}$} & \multirow{2}{*}{$\chi^{2}$} & \multirow{2}{*}{$p$} & \multirow{2}{*}{$\begin{array}{l}\text { Bonferroni } \\
\text { correction }\end{array}$} \\
\hline & & Experimental group & Comparative group & Control group & & & \\
\hline \multirow{6}{*}{$\begin{array}{l}\text { Sensory } \\
\text { processing }\end{array}$} & Auditory & $1.16 \pm 0.40$ & $1.33 \pm 0.51$ & $0.16 \pm 0.40$ & 10.96 & $.004^{*}$ & $1,2>3$ \\
\hline & Visual & $1.33 \pm 1.03$ & $0.66 \pm 0.51$ & $0.00 \pm 0.00$ & 8.84 & $.012^{*}$ & $1>2>3$ \\
\hline & Vestibular & $1.66 \pm 0.81$ & $1.16 \pm 0.75$ & $0.66 \pm 0.51$ & 5.48 & .064 & - \\
\hline & Touch & $1.83 \pm 1.72$ & $0.50 \pm 0.83$ & $0.00 \pm 0.00$ & 8.27 & $.016^{*}$ & $1>2,3$ \\
\hline & Multisensory & $083 \pm 0.98$ & $0.33 \pm 0.81$ & $-0.33 \pm 1.36$ & 2.79 & .247 & - \\
\hline & Oral & $0.16 \pm 0.40$ & $0.00 \pm 0.00$ & $0.16 \pm 0.40$ & 1.06 & .588 & - \\
\hline \multirow{5}{*}{$\begin{array}{l}\text { Sensory } \\
\text { modulation }\end{array}$} & Endurance/tone & $1.00 \pm 0.89$ & $0.66 \pm 0.81$ & $0.66 \pm 0.81$ & 0.68 & .723 & - \\
\hline & Position \& movement & $2.16 \pm 1.32$ & $1.50 \pm 0.54$ & $0.66 \pm 0.81$ & 5.74 & .057 & - \\
\hline & Activity level & $2.00 \pm 0.63$ & $0.33 \pm 0.81$ & $0.83 \pm 0.75$ & 8.84 & $.012^{*}$ & $1>2,3$ \\
\hline & Sensory input & $1.16 \pm 0.75$ & $0.83 \pm 0.40$ & $0.50 \pm 0.54$ & 3.28 & .194 & - \\
\hline & Visual input & $1.16 \pm 1.16$ & $0.66 \pm 0.51$ & $-0.16 \pm 0.75$ & 5.21 & .063 & - \\
\hline
\end{tabular}

${ }^{\mathrm{z}} 1=$ Experimental group; 2 = Comparative group; $3=$ Control group.

* $p<.05$. 
fect on all areas such as eye-hand coordination $(\mathrm{z}=-2.33, p=.020)$, copying $(\mathrm{z}=-2.07, p=.038)$, spatial relation $(\mathrm{z}=$ $-2.07, p=.038)$, and visual-motor speed $(\mathrm{z}=-2.12, p=.034)$ in the experimental group. In the comparative group, there was a significant effect on copying $(\mathrm{z}=-2.00, p=.046)$ and visual-motor speed $(\mathrm{z}=-2.70, p=.038)$ (Table 9).

By type of visual perception (Moon et al., 2003), forest psychomotorik significantly improved all areas of visual perception and visual motion such as spatial relation (eye-hand coordination, spatial relation) and form constancy (copying, visual closure, visual-motor speed, form constancy). On the other hand, indoor psychomotorik significantly improved visual perception areas in which intervention was decreased such as position in space and figure-ground. The results were similar to the study (Fjørtoft, 2001, 2004) that play activities in a natural space further develop motor skills of young children than the same play activities in an intentionally designed facility.

\section{Verification of the differences in visual perception and visual motion among groups}

As a result of calculating and testing the pretest-posttest score differences to determine the difference among groups, there were significant differences among groups in visual perception such as figure-ground $\left(\chi^{2}=6.02, p=.049\right)$ and form constancy $\left(\chi^{2}=9.29, p=.010\right)$, and visual motion such as eye-hand coordination $\left(\chi^{2}=9.29, p=.010\right)$. The experi-

Table 9. Changes in visual perception and visual motion after psychomotorik program within the group

\begin{tabular}{|c|c|c|c|c|c|c|}
\hline \multirow{2}{*}{\multicolumn{2}{|c|}{ Scale (sub-item) }} & \multirow{2}{*}{ Group $^{z}$} & \multicolumn{2}{|c|}{$\mathrm{M} \pm \mathrm{SD}$} & \multirow{2}{*}{$\mathrm{z}$} & \multirow{2}{*}{$p$} \\
\hline & & & Pre & Post & & \\
\hline \multirow{12}{*}{$\begin{array}{l}\text { Visual } \\
\text { perception }\end{array}$} & \multirow{3}{*}{ Position in space } & Experimental & $3.83 \pm 2.48$ & $4.83 \pm 2.63$ & -1.85 & .063 \\
\hline & & Comparative & $4.00 \pm 3.16$ & $5.00 \pm 3.03$ & -2.12 & $.034^{*}$ \\
\hline & & Control & $3.50 \pm 3.56$ & $3.83 \pm 3.65$ & -1.41 & .157 \\
\hline & \multirow{3}{*}{ Figure-ground } & Experimental & $4.83 \pm 3.06$ & $6.00 \pm 3.22$ & -1.89 & .059 \\
\hline & & Comparative & $5.33 \pm 1.36$ & $7.00 \pm 1.09$ & -2.27 & $.023^{*}$ \\
\hline & & Control & $5.83 \pm 3.18$ & $6.33 \pm 3.32$ & -1.73 & .083 \\
\hline & \multirow{3}{*}{ Visual closure } & Experimental & $4.83 \pm 4.02$ & $6.16 \pm 4.62$ & -2.07 & $.038^{*}$ \\
\hline & & Comparative & $3.66 \pm 3.77$ & $4.50 \pm 3.50$ & -1.63 & .102 \\
\hline & & Control & $4.00 \pm 3.94$ & $4.33 \pm 4.08$ & -1.41 & .157 \\
\hline & \multirow{3}{*}{ Form constancy } & Experimental & $6.00 \pm 2.28$ & $7.16 \pm 2.31$ & -2.33 & $.020^{*}$ \\
\hline & & Comparative & $6.66 \pm 1.03$ & $7.00 \pm .63$ & -2.07 & .157 \\
\hline & & Control & $6.44 \pm 2.80$ & $6.83 \pm 2.48$ & -1.73 & .317 \\
\hline \multirow{12}{*}{$\begin{array}{l}\text { Visual } \\
\text { motion }\end{array}$} & \multirow{3}{*}{ Eye-hand coordination } & Experimental & $2.50 \pm 1.87$ & $3.66 \pm 1.86$ & -2.33 & $.020^{*}$ \\
\hline & & Comparative & $3.00 \pm 1.54$ & $3.33 \pm 1.36$ & -1.41 & .157 \\
\hline & & Control & $3.00 \pm 1.54$ & $3.16 \pm 1.57$ & -1.00 & .317 \\
\hline & \multirow{3}{*}{ Copying } & Experimental & $7.00 \pm 2.60$ & $8.33 \pm 2.94$ & -2.07 & $.038^{*}$ \\
\hline & & Comparative & $6.66 \pm 3.14$ & $7.33 \pm 3.26$ & -2.00 & $.046^{*}$ \\
\hline & & Control & $6.66 \pm 3.93$ & $7.33 \pm 4.08$ & -2.00 & $.046^{*}$ \\
\hline & \multirow{3}{*}{ Spatial relation } & Experimental & $3.50 \pm 3.50$ & $4.60 \pm 3.72$ & -2.07 & $.038^{*}$ \\
\hline & & Comparative & $3.16 \pm 3.43$ & $3.66 \pm 3.66$ & -1.73 & .083 \\
\hline & & Control & $3.66 \pm 3.44$ & $4.00 \pm 3.89$ & -1.41 & .157 \\
\hline & \multirow{3}{*}{ Visual-motor speed } & Experimental & $7.66 \pm 3.88$ & $8.66 \pm 3.88$ & -2.12 & $.034^{*}$ \\
\hline & & Comparative & $7.83 \pm 1.72$ & $9.00 \pm 1.54$ & -2.70 & $.038^{*}$ \\
\hline & & Control & $7.50 \pm 2.82$ & $8.00 \pm 2.89$ & -1.73 & .083 \\
\hline
\end{tabular}

${ }_{\mathrm{z}}=6$ in each group.

* $p<.05$. 
Table 10. Verification of the differences in visual perception and motion after psychomotorik program among groups

\begin{tabular}{|c|c|c|c|c|c|c|c|}
\hline \multirow{2}{*}{ Sub-item } & & \multicolumn{3}{|c|}{$\mathrm{M} \pm \mathrm{SD}$} & \multirow{2}{*}{$\chi^{2}$} & \multirow{2}{*}{$p$} & \multirow{2}{*}{$\begin{array}{l}\text { Bonferroni } \\
\text { correction }^{z}\end{array}$} \\
\hline & & Experimental group & Comparative group & Control group & & & \\
\hline \multirow{4}{*}{$\begin{array}{l}\text { Visual } \\
\text { perception }\end{array}$} & Position in space & $1.00 \pm 0.89$ & $1.00 \pm 0.63$ & $0.16 \pm 0.40$ & 5.23 & .073 & - \\
\hline & Figure-ground & $1.16 \pm 0.98$ & $1.66 \pm 0.51$ & $0.50 \pm 0.54$ & 6.02 & $.049^{*}$ & $2>1,3$ \\
\hline & Visual closure & $1.33 \pm 0.81$ & $0.83 \pm 0.98$ & $0.16 \pm 0.40$ & 5.42 & .067 & - \\
\hline & Form constancy & $1.16 \pm 0.40$ & $0.33 \pm 0.51$ & $0.16 \pm 0.40$ & 9.29 & $.010^{*}$ & $1>2,3$ \\
\hline \multirow{4}{*}{$\begin{array}{l}\text { Visual } \\
\text { motion }\end{array}$} & Eye-hand coordination & $1.16 \pm 0.40$ & $0.33 \pm 0.51$ & $0.16 \pm 0.40$ & 9.29 & $.010^{*}$ & $1>2,3$ \\
\hline & Copying & $1.33 \pm 0.81$ & $0.66 \pm 0.51$ & $0.66 \pm 0.51$ & 3.53 & .171 & - \\
\hline & Spatial relation & $1.16 \pm 0.75$ & $0.50 \pm 0.54$ & $0.33 \pm 0.51$ & 4.47 & .107 & - \\
\hline & Visual-motor speed & $1.00 \pm 0.63$ & $1.16 \pm 0.75$ & $0.50 \pm 0.54$ & 3.12 & .210 & - \\
\hline
\end{tabular}

${ }^{\mathrm{z}} 1=$ Experimental group; 2 = Comparative group; $3=$ Control group.

${ }^{*} p<.05$.

mental group showed a more significant increase in form constancy and eye-hand coordination than the comparative group and control group, and the comparative group showed a more significant increase in figure-ground than the experimental group and control group (Table 10).

This is similar to the results of Chung (2014) and Jo et al. (2016) stating that there were positive effects on fine motor skills and visual perception mediated by natural objects. This result indicates that the program promotes form constancy (Frostig et al., 1964) that perceives the attributes and shapes even when they are different in terms of size, light and shade, texture and location as well as eye-hand coordination through the activities of moving and voluntarily finding natural objects and exploring and operating with five senses. Moreover, figure-ground, which was improved by indoor psychomotorik, is perceiving what is hidden in the general sensory background, showing a more significant improvement in exploration activities within limited space.

\section{Conclusion}

This study is to examine the effects of psychomotorik in the forest on sensory adaptation reaction and visual perception development of 18 children with intellectual disabilities. To this end, this study compared and analyzed results within and among groups through the pretest and posttest by categorizing children with disabilities living in a facility for persons with disabilities located in Seoul into three groups: the experimental group that participated in psychomotorik in the forest, the comparative group that participated in psychomotorik in an indoor treatment room, and the control group that did not participate at all. The results of this study can be summarized as follows.

First, there were significant changes in visual and auditory processing, position \& movement, sensory input and visual perception input in both forest and indoor psychomotorik. This indicates that senses and movements promote perception and stimulate cognitive development (Witt et al., 1988). Second, in the comparison among groups, forest psychomotorik significantly improved touch and activity level. This implies that the subjects more sensibly explore diverse natural objects in the forest than indoors, which improved touch processing (Andersen, 1996), and that moving around various geographical features and controlling physical movements and activities improved sensory modulation (Jeong and Rhie, 2011: Kang, 2019). Third, forest psychomotorik showed improvement in all areas of spatial relation and form constancy, especially in all areas of visual-motion. On the other hand, indoor psychomotorik showed improvement in areas of visual perception where intervention was reduced such as position in space and figure-ground. This is similar to the study 
(Fjørtoft, 2001, 2004) that play activities in a natural space further develop motor skills of young children than the same play activities in an intentionally designed facility, and that sensory and movement activities in the forest show greater effects on visual-motion. Fourth, in the comparison among groups, forest psychomotorik significantly improved form constancy (Frostig et al., 1964) that perceives the attributes and shapes even when they are different in terms of size, light and shade, texture and location as well as eye-hand coordination. This is similar to the results of Chung (2014) and Jo et al. (2016) stating that voluntarily finding and operating natural objects in the forest have positive effects on fine motor skills and visual perception. On the other hand, indoor psychomotorik is perceiving what is hidden in the general sensory background, showing a more significant improvement in exploration activities within limited space.

In conclusion, psychomotorik promoted senses and perception of children with disabilities, and psychomotorik in the forest was effective in improving touch, activity level, form constancy and eye-hand coordination, while indoor psychomotorik improved figure-ground with reduced movement. This indicates that psychomotorik using sensory factors and topography has positive effects on improving visual-motor skills through movements by promoting the fundamental sense of touch as well as activity level. This result implies that indoor and forest psychomotorik has positive effects on developing sensory adaptation response and visual perception of children with intellectual disabilities, and thus the forest can be used as a space for education and rehabilitation of children with disabilities.

This study is conducted on 18 children with intellectual disabilities by selecting only one living facility, and thus the results cannot be generalized to all intellectual disabilities. Furthermore, although the program was carried out for 9 months, it was carried out every other week and thus there were difficulties in maintaining durability as well as securing a stable activity space due to the variables of the forest space. It is necessary to further study the healing factors that can bring integrated improvement to physical, emotional, mental and social functions based on the forest, and rehabilitation programs that meet the needs of subjects with disabilities for each stage of the life cycle.

\section{References}

American Psychiatric Association. 2016. Diagnostic and statistical manual of mental disorders (DSM-5). Seoul, Korea: Hakjisa Press.

Andersen, E. 1996. Alles über Kindergärten [Everything about kindergartens.]. Ravensburg, Germany: Ravensburger Buchverlag.

Bradley, K. and D.B. Male. 2017. 'Forest school is muddy and I like it': Perspectives of young children with autism spectrum disorders, their parents and educational professionals. Educ. Child Psychol. 34(2):80-96.

Chung, M.J. 2014. The effects of natural material fingertip handcraft on fine motor skills of young children with brain lesions. J. Eco Early Child. Educ. Care 13(4):109-130.

Dunn, W. 1997. The impact of sensory processing abilities on the daily lives of young children and their families: A conceptual model. Infants Young Child. 9(4):23-35. https://doi.org/10.1097/00001163-199704000-00005

Fjørtoft, I. 2001. The natural environment as a playground for children: The impact of outdoor play activities in preprimary school children. Early Child. Educ. J. 29(2):111-117. https://doi.org/10.1023/a:1012576913074

Fjørtoft, I. 2004. Landscape as playscape: The effects of natural environments on children's play and motor development. Child. Youth Environ. 14(2):21-44.

Frostig, M.. M. Phyllis, D.W. Lefever, and J.R.B. Whittlesey. 1964. The marianne frostig developmental test of visual perception, 1963 Standardization. Percept. Mot. Skills 19(2):463-499. https://doi.org/10.2466/pms.1964.19.2.463

Hammill, D.D., L. Brown, and B.R. Bryant. 1992. A consumer's guide to tests in print (2nd ed.). Austin, TX: PRO-ED.

Hong, S.H., C.S. Shin, J.Y. Kim, Y.S. Jo, and M.R. Bang. 2016. Effects on the ADHD children's behavior and sociality by forest activities : A pilot study. J. Korean Soc. People Plants Environ. 19(2):139-147. 
https://doi.org/10.11628/ksppe.2016.19.2.139

Jeong, S.K. and S.J. Rhie. 2011. Effects of psychomotorik and sensory integration on sensory modulation and attention of children with ADHD tendency. J. Spec. Child. Educ. 13(4):331-356. https://doi.org/10.21075/kacsn.2011.13.4.331

Jo, Y.S., C.D. Koo, S.H. Hong, and J.H. You. 2016. The effect of forest activities on the movement skill and prosocial behavior of children with a developmental disability. J. Korean Soc. People Plants Environ. 19(6):659-666. https://doi.org/10.11628/ksppe.2016.19.6.659

Kang, E.H. 2019. The effect of the rope program in the forest on the sensory processing and visual perception of children with sensory control disorders. Master's thesis, Dankook University, Yongin-si, Korea.

Kim, S.K. and O.J. Kim. 1989. Vineland social maturity scale. Seoul, Korea: Jungangjeogseong Press.

Kim, Y.J. 2017. Effects of psychomotor application on quantified electroencephalogram and behavior of children with intellectual disability. Doctoral dissertation, Hanshin University, Osan, Korea.

Kiphard, E.J. 1989. Psychomotorik in Praxis und Theorie: ausgewählte Themen der Motopädagogik und Mototherapie: Mit 8 neuen Originalbeiträgen sowie zahlreichen Reprints der wichtigsten Arbeitendes Verfassers (2.Aufl.) [Psychomotor activity in practice and theory: selected topics of the Motopädagogik and Mototherapie: With 8 new original contributions and numerous reprints of the most important work of the author (2nd ed.)]. Gütersloh, Germany: Flöttmann.

Kiphard, E.J. 1998. Psychomotorik als "Meisterlehre" [Psychomotor activity "Master Teaching"]. Motorik 21 (3,S): 87-91.

Köllner, S. and C. Leinert. 1998. Waldkindergärten [Forest kindergartens]. Augusburg, Germany: RIWA Verlag.

Moon, S.B., K.E. Yeo, and Y.T. Jo. 2003. Korea developmental test of visual perception. Seoul, Korea: Hakjisa Press.

Schäfer, I. 1998. Von der psychomotorischen Idee zu den Gründungsjahren des Aktionskreises Psychomotorik [From the psychomotor idea to the founding years of the Aktionskreis Psychomotorik]. Motorik 21(3,S):82-86.

Schilling, F. 1986. Ansätze zu einer Konzeption der Mototherapie [Approaches to a conception of mototherapy]. Motorik 9(2):59-67.

Smith, L. and E. Thelen. 2003. Development as a dynamic system. Trends Cogn. Sci. 7(8):343-348. https://doi.org/10.1016/S1364-6613(03)00156-6

Song, H.J. 2013. The effects of psychomotor using coordination intervention for mental retardation children with developmental coordination disorder motor coordination and adjustment behaviors. J. Spec. Educ. Rehabil. Sci. 52(4):23-50.

Witt, J.C., S.N. Elliott, F.M. Gresham, and J.J. Kramer. 1988. Assessment of special children: Tests and the problemsolving process. Glenview, IL: Scott, Foresman \& Co.

Zachor, D.A., S. Vardi, E. S. Baron, M. I. Broda, N. Ginossar, and I. E. Ben. 2017. The effectiveness of an outdoor adventure programme for young children with autism spectrum disorder: A controlled study. Dev. Med. Child Neurol. 59(5):550-556. https://doi.org/10.1111/dmcn.13337

Zimmer, R. 2005. Sinneswahrnehmung [Sensory perception]. Freiburg, Germany: Herder Verlag. 